\title{
Pengembangan Karakter Kepemimpinan Siswa Melalui Rekonstruksi Focus Group Discussion Bermuatan Ajaran Asthabrata
}

\author{
Muhamad Danivul Haq ${ }^{1}$, M Ramli ${ }^{1}$, Andi Mappiare AT $^{1}$ \\ ${ }^{1}$ Bimbingan Konseling-Universitas Negeri Malang
}

\begin{tabular}{l}
\hline INFO ARTIKEL \\
\hline Riwayat Artikel: \\
Diterima: $28-01-2020$ \\
Disetujui: $15-06-2020$ \\
\hline
\end{tabular}

\section{Kata kunci:}

focus group discussion; asthabrata teachings; leadership character; focus group discussion; ajaran asthabrata; karakter kepemimpinan

\author{
Alamat Korespondensi: \\ Muhamad Danivul Haq \\ Bimbingan dan Konseling \\ Universitas Negeri Malang \\ Jalan Semarang 5 Malang \\ E-mail: danirembang@gmail.com
}

\begin{abstract}
This research aims to indentify the value of leadership in Asthabrata concept. The results are going to be constructed as theme to discussed as an effort to develop leadership characters of the students. This research is using qualitative approach which is descriptive. This kind of research is double hermeneutics. The primary data resources are from the study of Serat Rama which is Asthabrata concept came from. The secondary data resources are from direct interview from a Counselor teacher and a student where the school is used for research. The analysis research represent that there are eight values in Asthabrata concept. The values are adopt the nature such as 'the earth is manifest of sincerity', the water is manifest of justice, the wind is manifest of accuracy, the moon is manifest of tolerance, the sun is manifest of compassion, the ocean is manifest of wisdom, the star is manifest of firmness, and the fire is manifesf of responsibility. Focus grup discussion with eight theme from Asthabrata concept aims to increase the leadership character of the students consist of three steps, such as pre implementation, implementation and post implementation.
\end{abstract}

ABSTRAK

\begin{abstract}
Abstrak: Penelitian ini bertujuan untuk mengidentifikasi nilai-nilai kepemimpinan dalam ajaran Asthabrata. Hasil identifikasi tersebut selanjutnya dikonstruksi sebagai tema bahasan untuk didiskusikan bersama sebagai upaya untuk mengembangkan karakter kepemimpinan siswa. Penelitian ini menggunakan pendekatan kualitatif yang bersifat deskriptif. Penelitian ini menggunakan jenis penelitian hermenetik ganda. Sumber data primer berasal dari hasil telaah Serat Rama yang menjadi sumber ajaran Asthabrata. Sumber data sekunder yaitu hasil wawancara langsung dengan salah seorang guru BK dan siswa di sekolah yang menjadi lokasi penelitian. Hasil analisis menunjukkan bahwa terdapat delapan nilai dalam ajaran Asthabrata. Nilai tersebut mengadopsi sifat alam, yakni bumi wujud sifat keikhlasan, air wujud sifat adil, angin wujud sifat teliti, bulan wujud sifat toleransi, matahari wujud sifat welas asih, samudera wujud sifat bijaksana, bintang wujud sifat tegas, dan api wujud sifat tanggung jawab. Tahapan kegiatan teknik focus group discussion dengan menggunakan tema bahasan delapan ajaran Asthabrata untuk meningkatkan karakter kepemimpinan siswa terdiri dari tiga tahapan, yakni tahap pra pelaksanaan, tahap pelaksanaan, dan tahap pasca pelaksanaan.
\end{abstract}

Karya sastra Jawa lama merupakan sebuah hasil pemikiran yang turun-temurun diwariskan dalam kehidupan dan pemikiran masyarakat Jawa. Oleh sebab itu, penanaman spirit dari pemikiran adiluhung leluhur Jawa perlu untuk ditanamkan dalam kehidupan di sekolah, khususnya dalam konteks bimbingan dan konseling. Munandir (2009) mengemukakan bahwa penanaman nilai dalam pelaksanaan program bimbingan dan konseling di sekolah sangat menentukan manfaat dan kegunaan program tersebut di sekolah. Oleh sebab itu, penanaman kembali budaya Jawa dirasa mempunyai dampak positif. Hal ini senada dengan pendapat Hiu-Ha Chong \& Liu (2002) klien merupakan sosok individu yang unik yang dipengaruhi latar budaya dimana dia berasal. Selain itu, menurut Constantine et al., (2004) pengentasan permasalahan terkadang teori serta metode barat tak sepenuhnya dapat diaplikasikan untuk menelaah perilaku konseli di luar Negara barat. Melihat fakta tersebut menurut (Ren, 2012) bahwa individu dalam lingkup budaya ketimuran memiliki keunikan dan kekhasan tersendiri dalam aspek kedekatan dengan aplikasi budaya dalam dirinya. 
Adopsi budaya dalam penelitian ini adalah dengan telaah nilai luhur ajaran Asthabrata yang digunakan sebagai salah satu layanan bimbingan kelompok di sekolah. Nantinya ajaran tersebut akan diadopsi ke dalam teknik focus group discussion sebagai salah satu variasi teknik dalam pelaksanaan program bimbingan dan konseling di sekolah. Telaah budaya dalam kajian bimbingan dan konseling yang dipadukan dengan teknik Focus Group Discussion sebenarnya bukan hal baru, asumsi peneliti ini dikuatkan dengan beberapa penelitian antara lain dilakukan oleh (Krisphianti et al., 2016). Perbandingan Teknik Storytelling menggunakan media wayang topeng malang dan Metode Focus Group Discussion untuk meningkatkan karakter fairness siswa sekolah dasar. Selain itu, Hidayah \& Ramli (2017) mengungkapkan bahwa pengkajian nilai budaya perlu dilakukan, sebab beragamnya budaya yang ada di Indonesia. Suwarni (2016), Suhari (2012) juga mengungkapkan bahwa penguasaan konten budaya pada diri konselor diperlukan sebab beragamnya kultur konseli yang dihadapinya. Wangid (2010) menjelaskan bahwa konselor punya peran penting dalam pendidikan karakter di sekolah.

Kajian awal dalam ajaran asthabrata ditemukan delapan nilai luhur sebagai pedoman pengembangan karakter kepemimpinan berbasis budaya, nilai tersebut mengadopsi sifat alam semesta yang diwujudkan dalam perwatakan dewa serta mempunya karakter sifat masing-masing diantaranya (1) keikhlasan, (2) adil, (3) teliti, (4) toleransi, (5) welas asih, (6) bijaksana, (7) tegas, (8) tanggung jawab. Kedelapan nilai tersebut merupakan tema yang nantinya akan diangkat dalam rekonstruksi teknik focus group discussion sehingga dapat dimanfaatkan guru bk dalam pelaksanaan layanan bimbingan dan konseling di sekolah. Delapan nilai yang ditemukan di atas nantinya akan disatukan dalam proses layanan bimbingan kelompok pada siswa di sekolah dengan tema bahasan berlatar budaya dengan inti tema bahasan ajaran Asthabrata. Tujuan dari hal tersebut yakni sebagai media yang dapat digunakan untuk mencegah kemorosotan karakter kepemimpinan dan mengembangkan karakter kepemimpinan siswa yang dilandasi ajaran luhur budaya yang menjadi warisan leluhur masyarakat Jawa. Berkaca pada fakta di lapangan menunjukkan bahwa siswa dapat dikatakan sangat jauh dari nilai ideal yang harus dimiliki pemimpin baik bagi diri sendiri dan orang lain.

Selain itu, masalah juga muncul dari kurang beragamnya layanan bimbingan dan konseling di sekolah yang cenderung monoton sehingga pelaksanaan layanan kurang berjalan dengan optimal. Dari hal tersebut agaknya logis jika peneliti memasukkan nilai budaya dalam mengembangkan karakter siswa, sebab Sukmadinata (2007) mengemukakan bahwa seiring perkembangan zaman, tantangan yang harus dihadapi konselor adalah pengaruh nilai sosial dan budaya luar, sebab itu memasukkan nilai ajaran Asthabrata untuk mengembangkan karakter kepemimpinan siswa dirasa sangat pantas, hal ini senada dengan pendapat Hurlock (2009) bahwa budya memiliki peran dalam mengembangkan karakter individu. Hal tersebut juga diperkuat dengan pendapat Tilaar (2004) bahwa internalisasi nilai budaya daapt menjadi alternatif penguat karakter bangsa, Menelaah penelitian terdahulu agaknya dalam lingkup keilmuwan bimbingan dan konseling mulai akrab dengan pengadopsian nilai budaya dalam prosesnya. Khususnya kaitan dengan karakter penelitian dari Syamsuddin \& Juwanto (2019) menyatakan bahwa melalui layanan bimbingan kelompok bermuatan budaya Bengkulu efektif untuk meningkatkan karakter siswa SMA. Selain itu, pemanfaatan budaya dalam bimbingan dan konseling juga dibuktikan dari penelitian Wijaya (2017) dalam penelitiannya Bimbingan Kelompok Berbasis Budaya Buton (Falsafah Pobinci-Binciki Kuli) untuk Mengentaskan Perilaku Agresif Tawuran Siswa Kota Baubau. Hal ini dipertegas pula oleh Fajarini (2014) mengenai peranan budaya dalam pembentukan karakter siswa.

Nantinya hasil penelitian ini akan berbentuk prototype atau luaran prosedur teknik focus group discussion bermuatan ajaran asthabrata yang dapat digunakan dalam layanan bimbingan dan konseling di Sekolah Menengah Atas, khususnya pada SMA Negeri 1 Lasem Rembang. Hal ini berkaca dari penjelasan sebelumnya bahwa kurangnya ragam teknik layanan bimbingan kelompok di sekolah tersebut dan dirasa sangat monoton sehingga hasil penelitian ini dirasa mampu memunculkan semangat baru pada diri siswa untuk aktif dalam layanan bimbingan dan konseling di sekolah. Melalui diskusi, siswa akan lebih aktif mengemukakan pendapat serta berpikir sehingga proses layanan dapat berjalan optimal dari dua arah berbeda, yakni guru dan siswa sehingga rasa bosan dan kurang aktifnya siswa layanan bimbingan kelompok dapat diminimalisir karena proses layanan tidak terpaku pada ceramah yang menyebabkan siswa bosan dan kurang aktif seperti biasanya yang terjadi di lapangan.

\section{METODE}

Penelitian ini menggunakan pendekatan kualitatif dengan data analisis dan interpretasinya mengikuti kaidah-kaidah hermeneutika ganda (double hermeneutics). Penelitian ini memusatkan perhatian pada pemaknaan atau interpretasi ajaran Asthabrata yang tertuang dalam lakon wayang Wahyu Makutharama dan tertulis dalam Serat Rama karya R.Ng. Yasadipura terkait nilai kepemimpinan untuk memodifikasi karakter siswa. Hermeneutika merupakan tipe riset kualitatif yang memfokuskan pada pengalaman manusia dalam mencapai pemahaman akan suatu objek. Menurut Giddens (2004) hermeneutika ganda adalah arus timbal balik antara dunia sosial yang dilakukan oleh masyarakat dan wacana ilmiah yang dilakukan oleh ilmuwan sosial. Istilah hermeneutika ganda diberikan karena adanya proses ganda dalam proses interpretasi makna dari sumber yang diteliti. Alasan peneliti memilih tipe riset ini karena ajaran Asthabratha yang terkandung dalam lakon wayang Wahyu Makutharama adalah sebuah kearifan lokal yang pewarisannya dilakukan secara lisan, turun-temurun dari 
generasi ke generasi sehingga dibutuhkan pemaknaan yang tidak hanya melibatkan sebuah teks, namun juga praktik sosial, budaya, dan interaksi di masyarakat.

\section{HASIL}

Temuan dari telaah ini berupa delapan unsur nilai yang terkandung dalam ajaran Asthabrata. Nilai tersebut, meliputi (1) keikhlasan, (2) adil, (3) teliti, (4) toleransi, (5) welas asih, (6) bijaksana, (7) tegas, dan (8) tanggung jawab. Kedelapan nilai tersebut dapat dipaparkan sebagai berikut.

Pertama, keikhlasan menelaah dari ajaran Asthabrata keikhlasan merupakan manifestasi sifat bumi yang selalu ikhlas mememberikan manfaat meskipun terkadang manusia berlaku dzalim padanya. Mahambeg Mring Kisma merupakan perwujudan laku seorang pemimpin yang berlandaskan keikhlasan dalam segala aspek hidupnya. Kedua, adil bait ke-27 sampai ke-29 dalam Pupuh Pangkur merupakan penjelasan dari sifat adil dari manifestasi air, yang dalam kutipan syairnya digambarkan dengan meratani sajagad dapat biartikan menyebar kemanapun dan sifatnya tetap sama dimanapun berada, Mahambeg Mring Warih merupakan perwujudan laku air dalam ajaran Asthabrata. Ketiga, teliti bagaikan laku sifat angin atau dalam dikenal dengan Mahambeg Mring Samirono bahwa seorang pemimpin hendaknya dapat hidup di tengah masyarakat untuk mengetahui keadaan sekitarnya serta menghimpun informasi demi pengambilan keputusan yang dia butuhkan nanti. Sehingga keputusan terbaik demi kemaslahatan umat dapat tercipta. Keempat, toleransi sebuah kutipan lirik Pangkur yang berbunyi "apura serananira, ambeg santa sabuwana" yang didalamnya mengandung arti bahwa seorang pemimpin hendaknya menebar kasih sayang dan maaf pada siapapun, layaknya laku sang bulan atau bisa disebut Mahambeg Mring Condro yang menjadi simbol cinta kasih serta keindahan dalam kehidupan. Kelima, welas asih Mahambeg MringSuryo merupakan manifestasi sifat bathara surya yang dikenal dengan sifat palamartha atau welas asih, laksana mentari dengan welas asih berbagi sinarnya demi kehidupan di Bumi, sebab itu pemimpin hendaknya bersifat welas asih pada siapapun di sekitarnya. Keenam, bijaksana meneladani sifat samudera yang dengan bijaksana memilah apapun yang masuk kedalamnya demi sebuah keputusan bijak yang nantinya akan diambil, kutipan syair Pupuh pangkur menjelaskan bahwa sifat samudera yang den ajembar, den amot lawan den mengku, seperti itulah Mahambeg Mring Samodra atau meneladani sifat samudera. Ketujuh, tegas merupakan manifestasi sifat bintang yang merupakan lambing dari Dewa Yamadipati, dikenal dengan ketegasannya dalam menegakkan keadilan yang tak pandang siapapun itu, meneladani sifat tersebut seyogyanya seorang pemimpin hendaknya Mahambeg Mring Kartika yang dalam menegakkan aturan tak pilih kasih pada siapapun itu yang salah akan tetap salah dan yang benarpun akan tetap dalam posisi benar. Kedelapan, tanggung jawab perlambangan sifat api atau dikenal Mahambeg Mring Dahana sehingga dapat dikatakan seorang pemimpin hendaknya meniru sifat api yang selalu menyelesaikan tugas positif yang diembannya dengan tuntas sesuai dengan apa yang menjadi amanah pada dirinya.

Hasil dari kajian diatas akan digunakan sebagai tema bahasan dalam layanan bimbingan kelompok baik bersifat preventif maupun pengembangan yang dapat digunakan dalam layanan psikoedukasi menggunakan Teknik Focus Group Discussion, teknik tersebut nantinya akan terbagi menjadi tiga tahapan, yakni tahap pra pelaksanaan, tahap pelaksanaan, dan tahap pasca pelaksanaan. Pertama, tahap pra pelaksanaan atau persiapan merupakan langkah awal akan dilaksanakannya kegiatan, dalam tahap ini guru BK yang bertindak menjadi penyelenggara kegiatan akan melaksanakan usaha awal kegiatan antara lain menyiapkan undangan dan peserta, menyiapkan fasilitator dalam proses diskusi nantinya serta media lain yang dibutuhkan. Kedua, tahap pelaksanaan, pada tahap ini berisikan aktualisasi ataupun inti dari kegiatan yang telah dirancang sebelumnya, namun dalam tahap ini jika dibutuhkan sebelum masuk ke inti diskusi diberikan ice breaking sebagai pendingin suasana serta membangun keakraban kelompok. Ketiga, pasca pelaksanaan merupakan tahap follow up serta tindak lanjut dari kegiatan yang telah terjadi sehingga diketahui apakah perlu dilakukan lagi kegiatan tersebut atau tidak, ketika tidak diperlukan lagi diharapkan konselor memberikan sebuah penghargaan yang bermanfaat menambah kebanggaan siswa dan menjadi penarik bagi siswa lain untuk turut serta.

\section{PEMBAHASAN}

\section{Deskripsi Nilai Karakter Kepemimpinan dalam Ajaran Asthabrata}

Delapan nilai kepemimpinan yang teridentifikasi dalam ajaran asthabrata adalah (1) keikhlasan, (2) adil, (3) teliti, (4) toleransi, (5) welas asih, (6) bijaksana, (7) tegas, dan (8) tanggung jawab. Pertama, nilai keikhlasan yang merupakan perlambangan sifat bumi, wujud keikhlasan sifat bumi dituangkan dalam pupuh Pangkur bait ke-31 yakni agung mukti boga sarya ngenaki. Tan anggepok raganipun, kutipan tersebut dapat dimaknai bahwa dengan harta yang melimpah bumi tetap ikhlas berbagi tanpa mengharap balasan apapun itu. Pada praktiknya hal ini dapat masuk pada layanan pribadi di sekolah nantinya.

Kedua, nilai adil merupakan manifestasi sifat air dengan melihat sifat angin yang selalu mengisi setiap sendi dalam segala kehidupan serta dimanapun berada permukaan air akan tetap sama yang menjadikan dirinya dirasa sangat lekat dengan sifat adil yang tak pernah membedakan dimana ia berada. 
Ketiga, teliti merupakan perlambangan sifat dari angina. Hal ini berkaitan dengan sifat angin yang selalu ada di ruang manapun yang ada di jagad ini. Oleh sebab itu, sifat teliti angin muncul sebab dari membaurnya dirinya dimanapun hal ini berkaitan dengan pengambilan keputusan yang harus teliti dan demi kemaslahatan bersama.

Keempat, toleransi merupakan lambang keromantisan dari sifat bulan, dalam hal ini bulan menjadi lambang toleransi bagi seorang pemimpin, dalam ajaran asthabrata hal ini disebut Mahambeg Mring Condro atau meniru sifat bulan. Senada dengan Nehushtan (2007) mengemukakan bahwa individu seyogyanya memiliki sikap toleransi agar mampu menempatkan diri sesuai dengan keadaan lingkungan.

Kelima, welas asih yang dalam Serat Rama dikenal dengan laku palamarta yang dapat diartikan welas asih pada semua isi alam, menelaah isi serat rama yang menjelaskan bahwa welas asih merupakan perlambangan sifat dari matahari yang dengan welas asih menyinari bumi dan menumbuhkan kehidupan didalamnya, dalam kaitannya dengan karakter sebuah penelitian dari Hidayati, Salma, \& Suparno (2018) berkaitan dengan welas asih untuk menumbuhkan empati pada anak ternyata efektif walaupun tak signifikan.

Keenam, bijaksana merupakan wujud dari sikap samudera yang dengan bijak menampung semua hal positif dan negatif yang diterimanya serta memilah hal manakah yang akan berguna bagi makhluk hidup. Menurut Sahrani (2019) bijaksana adalah wujud sinkronisasi akal budi, pikiran, tingkah laku serta perasaan yang memunculkan sebuah keharmonisan antara individu dengan lingkungan dimana dirinya berada.

Ketujuh, tegas yang menjadi personifikasi bintang yang dalam serat rama diceritakan dikuasai oleh Dewa Yama Dipati dan mengemban tugas menegakkan keadilan, jadi sifatnya yang tegas tak dapat digoyahkan menjadi modal kuatnya menegakkan keadilan di jagad ini. Menurut Suharso \& Retnoningsih (2005) tegas merupakan tindakan yang tidak samar, tanpa ragu serta tak ada kebimbangan sedikitpun. Sebuah penelitian oleh Fitria \& Sukma (2013) menunjukkan ketegasan dalam hal positif akan menumbuhkan kenyamanan bagi sekitar. Hal ini ditunjukkan dengan salah satu siswa SMP di Padang yang siswanya merasa nyaman ketika mendapat tindakan tegas dari guru ketika mereka melanggar.

Kedelapan, tanggung jawab yang menjadi perlambangan dari sikap api, sikap tanggung jawab merupakan aspek penting dalam karakter dalam diri individu, sebab tanggung jawab merupakan sebuah bukti tentang kesungguhan dalam mengemban sebuah amanah. Hal ini ditunjukan oleh Christine Masada H.T (2016) dalam sebuah penelitannya menunjukkan siswa yang tak bertanggung jawab terhadap pembelajaran memunculkan kecenderungan sifat mencontek.

\section{Rekonstruksi Teknik Focus Group Discussion Bermuatan Ajaran Asthabrata}

Pendidikan karakter yang memanfaatkan aspek kebudayaan sebenarnya sudah banyak dilakukan. Penelitian oleh Suryaman (2010) menejelaskan bahwa melalui pendidikan sastra karakter anak dapat ditumbuhkan. Berkaitan dengan penelitian ini yang menggunakan aspek sastra Jawa dalam wujud serat Suhari (2012) menjelaskan tentang ajaran Asthabrata sebagai media membangun karakter bangsa melalui kearifan local. Selain itu, berkaitan dengan ajaran Asthabrata, penelitian dari As'ad et al., (2011) menunjukkan intisari dari ajaran tersebut sebagai media mengembangkan sikap kepemimpinan.

Focus Group Discussion merupakan salah satu varian teknik dalam bimbingan kelompok dirasa sangat memungkinkan untuk memasukkan nilai budaya yang menjadi konten isi dari kegiatan tersebut. Hal ini menurut Logren et al., (2017) dalam proses diskusi kelompok tersebut anggota kelompok dapat saling mengevaluasi serta bertukar pikiran sehingga pesan yang ada dalam tema bahasan sangat mungkin tersampaikan. Selain itu, Meleady et al (2013) memberikan penuturan bahwa diskusi dapat membantu pemecahan masalah pada diri individu didalamnya. Resnick et al (1977) menjelaskan bahwa optimalnya bimbingan kelompok adalah pada komunikasi dalam kelompok serta dinamika kelompok didalamnya. Menurut Paternotte (2014) dalam kelompok keaktifan anggota dalam bertukar pemikiran serta informasi akan semakin menambah tingkat kohesivitas dalam kelompok tersebut.

Berdasarkan pada sejumlah kajian di atas salah satu upaya yang dilakukan untuk mengembangkan karakter kepemimpinan siswa, yaitu dengan internalisasi nilai budaya yang terkandung dalam ajaran Asthabrata yang diimplikasikan dalam konten teknik Focus Group Discussion dalam layanan bimbingan kelompok di sekolah. Penggunaan teknik tersebut dimaksudkan untuk memancing peran aktif siswa sehingga terjadi komunikasi dua arah dalam proses layanan tersebut karena dalam fakta lapangan sebelumnya layanan bimbingan kelompok dinilai kurang variatif sebab terlalu monoton pada teknik yang digunakan.

\section{SIMPULAN}

Nilai yang ditemukan berdasarkan hasil telaah dalam ajaran Asthabrata ada delapan nilai, yakni (1) keihklasan, (2) adil, (3) teliti, (4) toleransi, (5) welas asih, (6) bijaksana, (7) tegas, dan (8) tanggung jawab. Kedelapan nilai tersebut disatukan dalam karakter kepemimpinan ideal yang nantinya akan dijadikan tema bahasan dalam layanan bimbingan kelompok dengan teknik focus group discussion. Teknik tersebut terbagi menjadi tiga tahapan, yakni (1) tahap pra pelaksanaan atau persiapan awal, (2) tahap pelaksanaan yakni kegiatan inti dari teknik tersebut, dan (3) pasca pelaksanaan berkaitan tentang tindak lanjut setelah kegiatan. 
Adapun saran yang dapat diberikan kepada guru BK di SMA Negeri 1 Lasem, hasil penelitian ini diharapkan menjadi salah satu ragam baru dalam pemberian layanan bimbingan kelompok di sekolah. Kepada peneliti dan pegiat bimbingan konseling diharapkan dapat lebih jauh mengkaji penelitian ini menggunakan metode pengembangan agar dapat mengembangkan secara optimal hasil penelitian ini. Selain itu, diharapkan juga pengkajian dengan kaidah metodologi eksperimen dalam kajian penelitian kuantitatif sehingga dapat diketahui seberapa efektif hasil penelitian ini dalam meningkatkan karakter kepemimpinan siswa.

\section{DAFTAR RUJUKAN}

As'ad, M., Anggoro, W., \& Virdanianty, M. (2011). Studi Eksplorasi Konstrak Kepemimpinan Model Jawa: Asta Brata. Jurnal Psikologi UGM, 38(2), 228-239. https://doi.org/10.22146/jpsi.7655

Christine Masada H.T. (2016). Faktor Pemengaruh Perilaku Siswa dan Mahasiswa Menyontek. SOSIO-E-KONS, 8(3), $227-233$.

Constantine, M. G., Myers, L. J., Kindaichi, M., \& Moore, J. L. (2004). Exploring Indigenous Mental Health Practices: The Roles of Healers and Helpers in Promoting Well-Being in People of Color. Counseling and Values, 48(2), 110-125. https://doi.org/10.1002/j.2161-007X.2004.tb00238.x

Fajarini, U. (2014). Peranan Kearifan Lokal Dalam Pendidikan Karakter. SOSIO DIDAKTIKA: Social Science Education Journal, 1(2). https://doi.org/10.15408/sd.v1i2.1225

Hidayati, F., Salma., \& Suparno. (2018). Pengembangan Model Pembelajaran Empati Anak melalui Pendidikan Karakter Welas Asih Diri. Seminar Nasional dan Call for Paper "Membangun Sinergitas Keluarga dan Sekolah Menuju PAUD Berkualitas, 56-64.

Hidayah, N., \& Ramli, M. (2017). Need of Cognitive-Behavior Counseling Model Based on Local Wisdom to Improve Meaning of Life of Madurese Culture Junior High School Students. 128(Icet), 301-307. https://doi.org/10.2991/icet-17.2017.53

Hiu-Ha Chong, F., \& Liu, H.-Y. (2002). Indigenous Counseling in the Chinese Cultural Context: Experience Transformed Model. Asian Journal of Counselling, 9(2), 49-68.

Krisphianti, Y. D., Hidayah, N., \& Irtadji, M. (2016). Efektivitas Teknik Storytelling menggunakan Media Wayang Topeng Malang untuk Meningkatkan Karakter Fairness Siswa Sekolah Dasar. PSIKOPEDAGOGIA Jurnal Bimbingan dan Konseling, 5(1), 17. https://doi.org/10.12928/psikopedagogia.v5i1.4478

Logren, A., Ruusuvuori, J., \& Laitinen, J. (2017). Self-Reflective Talk in Group Counselling. Discourse Studies, 19(4), 422440. https://doi.org/10.1177/1461445617706771

Meleady, R., Hopthrow, T., \& Crisp, R. J. (2013). The Group Discussion Effect: Integrative Processes and Suggestions for Implementation. Personality and Social Psychology Review, 17(1), 56-71. https://doi.org/10.1177/1088868312456744

Nehushtan, Y. (2007). The Limits of Tolerance : A Substantive-Liberal Perspective. 20(2), 230-257. https://doi.org/https://doi.org/10.1111/j.1467-9337.2007.00357.x

Paternotte, C. (2014). Minimal Cooperation. Philosophy of the Social Sciences, 44(1), 45-73. https://doi.org/10.1177/0048393112457428

Ren, Z. (2012). Spirituality and Community in Times of Crisis: Encountering Spirituality in Indigenous Trauma Therapy. Pastoral Psychology, 61(5-6), 975-991. https://doi.org/10.1007/s11089-012-0440-5

Resnick, R. J., Lira, F., \& Wallace, J. H. (1977). On The Effectiveness of Group Counseling: A Look at the Group Leader in the Correctional Setting. Criminal Justice and Behavior, 4(1), 77-85. https://doi.org/10.1177/009385487700400106

Suhari. (2012). Nilai-Nilai Ajaran Hastabrata Dalam Lakon Pewayangan Makutharama sebagai Media Membangun Karakter Bangasa. Jurnal Budaya Nusantara, 1(2), 154-160.

Suryaman. (2010). Pendidikan Karakter melalui Pembelajaran Sastra. Cakrawala Pendidikan, 1(3), 112-126. https://doi.org/10.21831/cp.v1i3.240

Suwarni. (2016). Memahami Perbedaan sebagai Sarana Konseling Lintas Budaya. Konseling Religi: Jurnal Bimbingan Konseling Islam, 7(1), 117-138.

Syamsuddin., \& Juwanto. (2019). Model Layanan Bimbingan Kelompok Berbasis Budaya untuk Meningkatkan Nilai-Nilai Karakter Siswa di SMA Pembangunan Kota Bengkulu. Jurnal Psikodidaktika, 4(2), 36-47. https://doi.org/https://doi.org/10.32663/psikodidaktika.v4i2.966

Wangid. (2010). Peran Konselor Sekolah Dalam Pendidikan Karakter. Cakrawala Pendidikan, 1(3), $173-186$. https://doi.org/10.21831/cp.v1i3.244

Wijaya, R. S. (2017). Bimbingan Kelompok Berbasis Budaya Buton (Falsafah Pobinci-Binciki Kuli) untuk Mengentaskan Perilaku Agresif. Prosiding Seminar Bimbingan dan Konseling, 1(1), 319-331. 